\title{
A FLOW AND PRESSURE DISTRIBUTION OF APR+ REACTOR UNDER THE 4-PUMP RUNNING CONDITIONS WITH A BALANCED FLOW RATE
}

\author{
D.J. EUH, K.H.KIM, Y.J. YOUN, J.H.BAE, I.C.CHU, J.T.KIM, H.S.KANG, H.S.CHOI, S.T. LEE, and T.S. KWON* \\ Korea Atomic Energy Research Institute \\ Daedeok-daero 1045, Yuseong, Daejeon, 305-353, Korea \\ "Corresponding author. E-mail : tskwon@kaeri.re.kr
}

Received October 17, 2012

In order to quantify the flow distribution characteristics of APR+ reactor, a test was performed on a test facility, ACOP

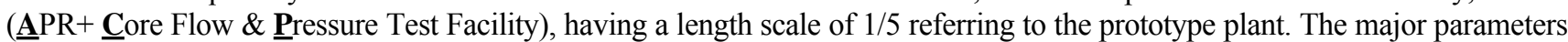
are core inlet flow and outlet pressure distribution and sectional pressure drops along the major flow path inside reactor vessel. To preserve the flow characteristics of prototype plant, the test facility was designed based on a preservation of major flow path geometry. An Euler number is considered as primary dimensionless parameter, which is conserved with a 1/40.9 of Reynolds number scaling ratio. ACOP simplifies each fuel assembly into a hydraulic simulator having the same axial flow resistance and lateral cross flow characteristics. In order to supply boundary condition to estimate thermal margins of the reactor, the distribution of inlet core flow and core exit pressure were measured in each of 257 fuel assembly simulators. In total, 584 points of static pressure and differential pressures were measured with a limited number of differential pressure transmitters by developing a sequential operation system of valves. In the current study, reactor flow characteristics under the balanced fourcold leg flow conditions at each of the cold legs were quantified, which is a part of the test matrix composing the APR+ flow distribution test program. The final identification of the reactor flow distribution was obtained by ensemble averaging 15 independent test data. The details of the design of the test facility, experiment, and data analysis are included in the current paper.

KEYWORDS : APR+, Flow Distribution, Pressure Distribution, Thermal Margin, Safety Analysis, Pressure Drop, Euler Number, Renolds Number

\section{INTRODUCTION}

The performance and safety of the nuclear reactor can be analyzed and demonstrated based on appropriate input data for various thermal hydraulic condition of the reactor system. The core thermal margin is evaluated based on core inlet flow and core outlet pressure distribution at each of the fuel assemblies. The performance and safety analysis of the reactor's transient condition can be performed based on the information of pressure loss along the major flow path in the primary system. The hydraulic characteristics of a reactor system can be evaluated by using mathematical models, or an experimental apparatus with an adaptation of a proper scaling theory. Although mathematical tools have been developed for the complex geometry of systems like nuclear reactors over the past several decades, those still need to be improved to verify their accuracy.

Hetsroni (1967) proposed four principal parameters for a hydraulic model representing hydraulics of prototype nuclear reactor, which are geometry, relative roughness,
Reynolds number, and Euler number. They concluded that the Euler number should be similar in the prototype and model under the preservation of the aspect ratio on the flow path. The effect of the Reynolds number at a sufficient turbulent region on the Euler number is rather small, since the dependency of the form and frictional loss coefficients on the Reynolds number is considered to be small.

ABB-CE had carried out several reactor flow model test programs, mostly for its prototype reactors. In the period between 1978-1980, when the internal design of the prototype System 80 reactor was being developed, a series of tests were run using a 3/16 scale reactor model. (Referring to Lee et al. (2001)) Lee et al (1991) performed experimental studies using a 1/5.03 scale reactor flow model of Yong-gwang nuclear units 3 and 4 . They showed that the measured data met the acceptance criteria and were suitable for their intended use in terms of performance and safety analyses. Euh et al (2002a) constructed a test apparatus for the SMART reactor which is a modular type of an integral reactor with a $1 / 5$ linear scale ratio. Their tests included the reactor flow distributions under the 
balanced and the 5\% unbalanced 4-pump flow conditions and the single RCP failure conditions, which are similar to the test requirements of this study.

To simulate the hydraulic performance of $\mathrm{APR}+$, the ACOP was established.APR + has been designed with a power production capacity of $1500 \mathrm{MW}$, and adopts advanced concepts for safety system such as ECBD (Emergency Core Barrel Duct) for direct vessel injection of the emergency core cooling water and passive auxiliary feedwater system. (Song et al, 2010, Kwon et al., 2012a, b) Since the present study focuses on the hydraulic features of the reactor, the operating conditions were set at low pressure and temperature. The design was performed on the basis of the conservation of the Euler number, which corresponds to the hydraulic resistance based on the similitude of flow geometry. In order to preserve the flow distribution characteristics, APR + reactor and inner structures were linearly reduced at a scaling ratio of $1 / 5 \mathrm{in}$ the test facility by referred to the previous studies. The Euler number has a good similitude between two systems if the flow conditions maintain sufficiently high Reynolds number. The test conditions adopted a half velocity scale of the APR+ reactor, which yields a 1/40.9 scaling ratio of Reynolds number when compared with the prototype reactor. The major parameters tested can be classified into those inside and outside the reactor vessel. In the reactor vessel, the static pressures, differential pressures at the segmented interval along the major flow path, and the core inlet flow distribution are important parameters to be measured. APR+ is two-loop system, which has four cold legs and two hot legs. A flow rate, temperature and static pressure were measured at each leg for the boundary condition of the reactor vessel.

The purposes of the present study are (1) to measure the pressure distribution factor at the core inlet for an analysis of the reactor's thermal margin, and (2) to measure the segmental and total pressure losses along the main coolant flow paths from the cold leg to the hot leg. The scaling method and design features of the ACOP facilities, including instrumentation, are introduced in this paper. For the APR+ reactor flow distribution, the following three types of test cases were progressed: (1) balanced four-cold leg flow conditions (2) $5 \%$ unbalanced fourcold leg flow conditions and (3) three RCP flow conditions due to a single RCP failure. Among them, the first grouped tests that have balanced flow rate at each cold leg were performed in the current study. The identification of the reactor flow distribution for the balanced cold leg flow conditions was obtained by ensemble averaging process with 15 independent tests for the reference conditions.

\section{TEST FASCILITIES}

\subsection{Scaling Method}

The test facility, named ACOP, was designed based on the concept of Euler number conservation. The Euler number is defined as a ratio of pressure drop to the dynamic force, which can be considered as a pressure drop coefficient. Two types of similarities, which are geometric and dynamic similarities, are important. The geometric similarity requires that all linear dimensions of the reactor and the model be scaled by a constant. The dynamic similarity between reactor and model can be obtained when the forces acting on similar volume elements have the same ratio (Lee et al., 1991). While all these requirements must be met for strict dynamic similarity, some compromises are necessary in areas where previous experiments indicate that violation of the laws of similitude will not seriously impair the value of the test.

Table 1 summarizes the scaling ratio of major design parameters applied to the ACOP facilities. The APR+ design was linearly scaled to a $1 / 5$ ratio in the test facility while the geometrical similarity is conserved. To achieve a sufficiently large Reynolds number of the flow conditions, the test conditions of the ACOP are determined to have a 1/40.9 of Reynolds number scale ratio, which corresponds to around a half velocity of the prototype reactor. The scaling ratio that was shown in Table 1 was based on the properties at $0.2 \mathrm{MPa}$ and $60^{\circ} \mathrm{C}$. The flow geometry inside the fuel assemblies was not preserved since each fuel assembly was restructured using a simplified geometry of the core simulator. The role of the core simulator is preservation of the axial core pressure drop and lateral cross flow characteristics between the adjacent fuel assemblies. The importance of the Reynolds number at the core region is placed on its magnitude at the model. Normally, core flow has a relatively lower Reynolds number than the other regions since the hydraulic diameter is very small. Since the core simulator has a large diameter, the Reynolds number at the core region of ACOP is analyzed as $1 / 2.98$ of the APR+ reactor.

\subsection{Reactor Vessel and Inner Structures}

The reactor vessel and inner structures of ACOP facility is a linearly scaled copy of the APR+ reactor. (KHNP, 2011) The same number of core simulators as $\mathrm{APR}+$ fuel assemblies were scaled, assembled and configured in the test section. The upper and lower core structures were manufactured with the same shape as those of APR+, except for the upper head region. Figure 1 shows the design feature of internal strucutures of the reactor vessel. The reactor simulator consists of vessel, core barrel, core simulator and pressure impulse lines, core lower structures, and upper guide structures. An emergency core barrel duct (ECBD) was installed on the outer surface of the core barrel based on the prototype design. The duct has a same curvature of APR+ with $11 \mathrm{~mm}$ gap and was made of $1 \mathrm{~mm}$ thickness of stainless steel. The intake hole has $86 \mathrm{~mm}$ of diameter in the facility.

The flow geometry along the major flow path except for the core, which includescold leg nozzle, downcomer, 


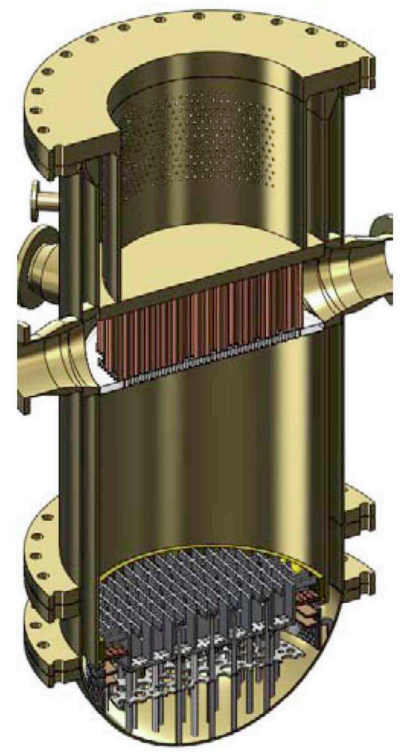

Fig. 1. ACOP Test Section (Reactor Simulator)

lower head, lower plenum, upper plenum and hot leg nozzle, were preserved in shape with a length scale of $1 / 5$ of APR+. The upper head region was neglected since the current test does not simulate the core bypass flow. The core shroud baffle region was also isolated from the main flow path by blocking the core shroud inlet as well as core simulator outer side windows. Since the test focuses on the hydraulic study of the plant, the facility was designed for lower pressure and temperature conditions. Therefore, the thickness of reactor vessel outer wall was not preserved, while, the internal structure had its thickness reduced by the scaling ratio applied for the overall design of the facility so that the internal volume and flow area could be preserved. Direction of DVI nozzles have relative angle of $25^{\circ}$ compared to the cold leg nozzle, which is a $\mathrm{APR}+$ design changed from APR1400.

The 257 fuel assemblies composing the APR + core region were replaced by a same number of core simulators representing individual fuel assembly. The core simualtor has a venturi shape of inlet part to measure the inlet water flow rate as shown in figure 2 and 3. (Euh et al, 2011, 2012b, Bae et al, 2011) The axial flow resistence was set at the scaled value of APR + by controlling the size of the orifices located at the four different downsteam elevations. The design flow condition was set at $1 / 2$ velocity of APR+ core flow which has a $1 / 2.76$ Reynolds number ratio. The pressure drop ratio of core simulator is also followed by overall pressure drop ratio summarized in Table 1. The flow resistence of each core simulator was precisely calibrated in advance of being assembled into the reactor vessel. (Kim et al, 2012) A table of the flow discharge coefficients was prepared for from $40 \%$ to $130 \%$ of reference scaled flow rate at the core simulator at the CALIP $\underline{\text { CAlibration Loop }}$

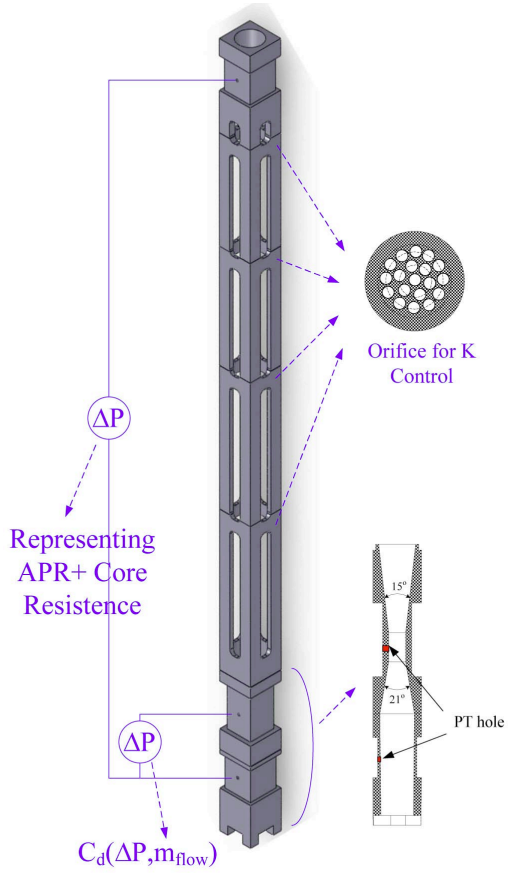

Fig. 2. Design of Core Simulator

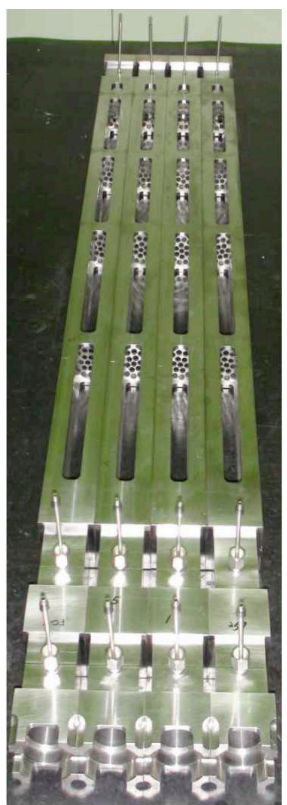

Fig. 3. Photograph of Core Simulator

for Internal Pressure drop) test facility.Therefore, the core inlet flow can be achieved and measured by the differential pressure at the venturi of the core simulator and discharge coefficients of each venturi. Figure 4 showsaveraged flow discharge coefficients of core simulators according to the Reynolds numbers. The consistency of the discharge coefficients among the various core simulators should be 
Table 1. Summary of Parameter Scaling

\begin{tabular}{l|c|c|c}
\hline & APR + & Scaling Ratio & ACOP \\
\hline Temperature, ${ }^{\circ} \mathrm{C}$ & 310 & - & 60 \\
\hline Pressure, $\mathrm{MPa}$ & 15 & - & 0.2 \\
\hline Length Ratio, - & 1 & $l_{R}$ & $1 / 5$ \\
\hline Height Ratio, - & 1 & $l_{R}$ & $1 / 5$ \\
\hline Diameter or Width Ratio, - & 1 & $l_{R}$ & $1 / 5$ \\
\hline Area Ratio, - & 1 & $l_{R}^{2}$ & $1 / 25$ \\
\hline Volume Ratio, - & 1 & $l_{R}^{3}$ & $1 / 125$ \\
\hline Aspect Ratio, - & 1 & 1 & 1.0 \\
\hline Velocity Ratio, - & 1 & $V_{R}$ & $1 / 2.17$ \\
\hline Mass Flow Ratio, - & 1 & $\rho_{R} V_{R} l_{R}^{2}$ & $1 / 38.9$ \\
\hline Density, kg/m ${ }^{3}$ & 705.8 & $\rho_{R}$ & 983.2 \\
\hline Density Ratio & 1 & $\rho_{R}$ & 1.39 \\
\hline Viscosity, Ns/m ${ }^{2}$ & $8.88 \mathrm{e}-5$ & $\mu_{R}$ & $4.66 \mathrm{e}-04$ \\
\hline Viscosity Ratio, - & 1 & $\mu_{R}$ & 5.26 \\
\hline Ex-Core Re Ratio, - & 1 & $\rho_{R} V_{R} D_{R}$ & $1 / 40.9$ \\
\hline DP Ratio, - & 1 & $\rho_{R} V_{R}^{2}$ & $1 / 3.38$ \\
\hline
\end{tabular}

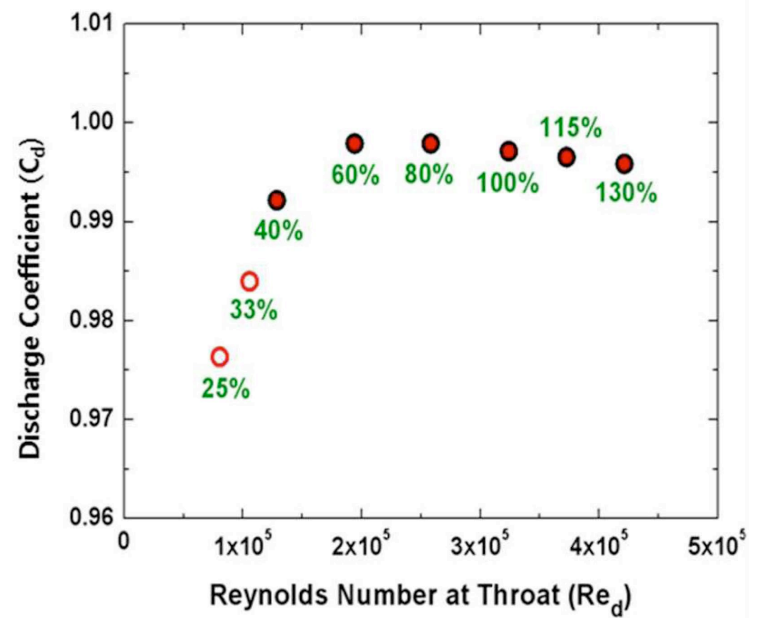

Fig. 4. Averaged Discharge Coefficients of Core Simulator

preserved to represent the APR+ core crossflow characteristics, which is related to the fabrication accuracy of the core simulator. Figure 5 shows a typical scatter diagram of the discharge coefficients of total core simulators for the nominal flow conditions. The figure shows a standard deviation less than $0.4 \%$ of average value, which means that the accurate core flow distribution can be obtained by using the core simulators.

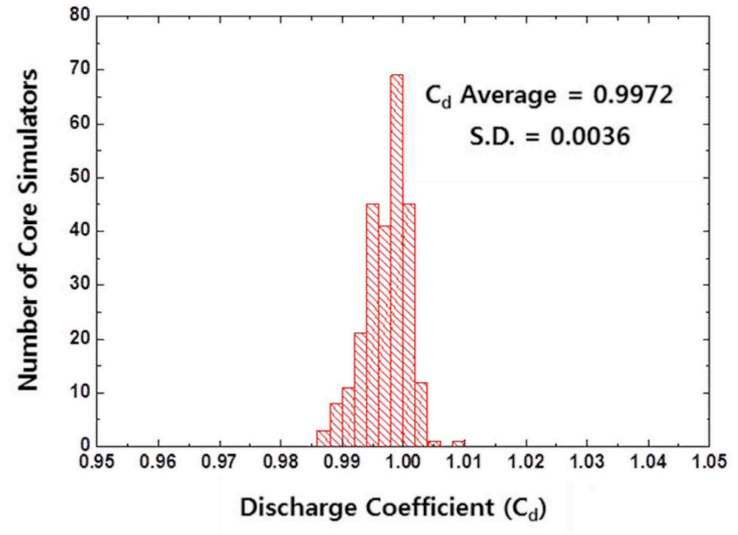

Fig. 5. Scatter Diagram of Discharge Coefficients

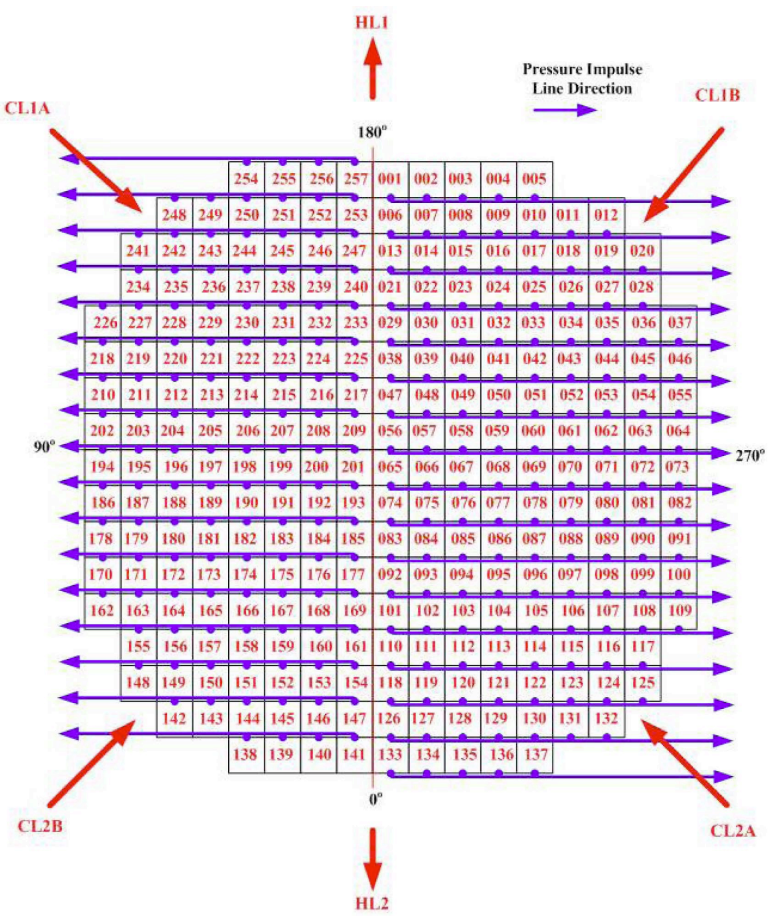

Fig. 6. Core Configuration and Pressure Impulse Line Direction

To setup the core simulators in the reactor vessel, three pressure impulse lines per core simulator should be drawn out and connected to the pressure transmitters without any significant interference of the reactor flow. To minimize the perturbation due to instrumentation, a total of 772 pressure impulse lines, were guided inside the core shroud region and drawn out from the top of the test section. Since the core shroud region was designed to be isolated from the main flow region, the pressure impulse lines do not affect the reactor flow. Figure 6 shows the configuration of the core simulators and drawing-out direction of pressure impulse lines. However, interference 


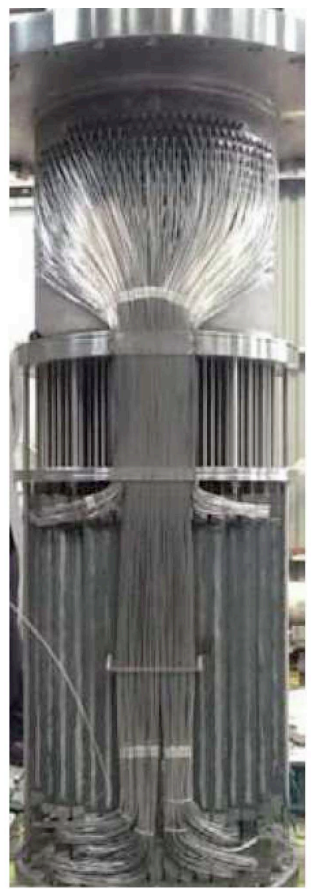

Fig. 7. Drawing-out Configuration of Pressure Impulse Lines from Core Simulators

at the upper plenum is unavoidable since the pressure impulse line should go through the region to the vessel top. Therefore, a guide duct was setup inside the core shroud region at a perpendicular angle to each hot leg direction of the upper plenum. Figure 7 shows the drawing-out configuration of pressure impulse lines from core simulators.

\subsection{Piping System}

Figure 8 shows a schematic of the APR+ reactor flow distribution test facility, ACOP. The four independent pumps were established for the individual cold leg flow. Each pump is a mechanical seal-type centrifugal type having $498 \mathrm{~m}^{3} / \mathrm{hr}$ of rated flow capacity, $45 \mathrm{~m}$ of head, $1750 \mathrm{rpm}$ and $90 \mathrm{~kW}$ of power were setup for the water circulation. Each hot leg flow is branched and directly entered into the pump suction. Since the test is focused on the hydraulics, steam generators were not considered.The piping configuration connected to the reactor vessel was also conserved in the test facility as shown in figure 9 .

\subsection{Instrumentation and Control System}

Figure 10 shows an instrumentation and control diagram of the ACOP loop system. The temperature is controlled at each cold leg by controlling the heat exchanger's secondary flow rate by referring to the temperature measured by the RTD downstream of the heat exchanger. To reduce the pressure drop across the heat exchangers, the primary side was designed as once-through tube types. The cold leg and hot flow are measured by

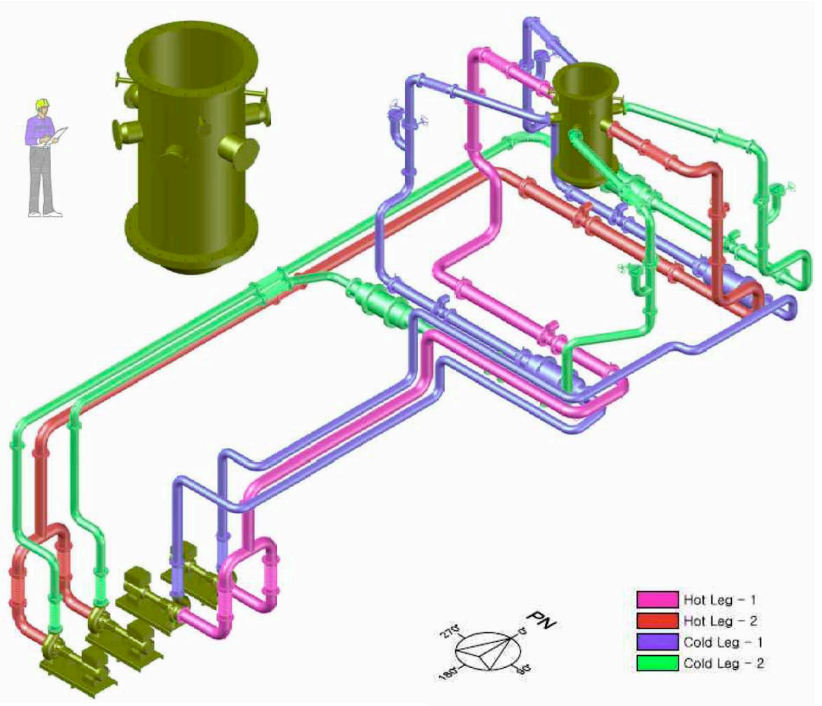

Fig. 8. Bird's eye View of ACOP Test Facility.

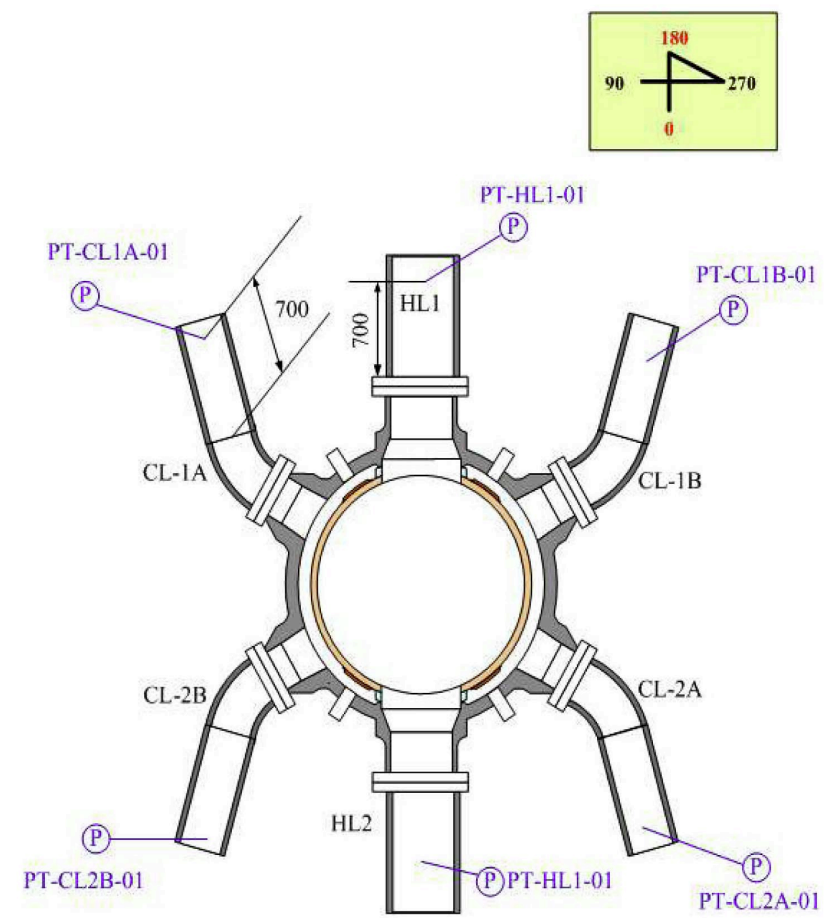

Fig. 9. Piping Connected to the Reactor Vessel

vortex flow meters installed at all the legs. The volumetric flow rate measured was converted with the density referred to the temperature and pressure measured at each leg. The desired flow rate can be achieved by controlling pump rotational speed using an inverter. The system pressure is controlled by valves connected to the surge tank.

Figure 11 shows the instrumentation applied to the 


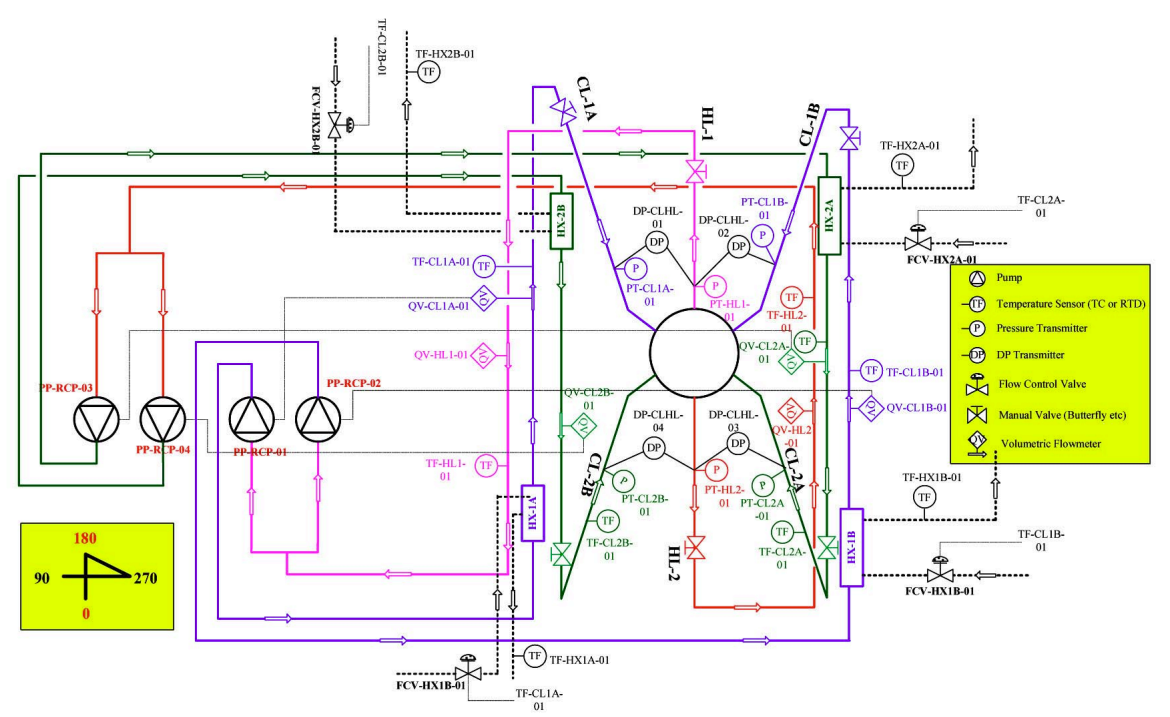

Fig. 10. Instrumentation and Control Diagram of ACOP Loop

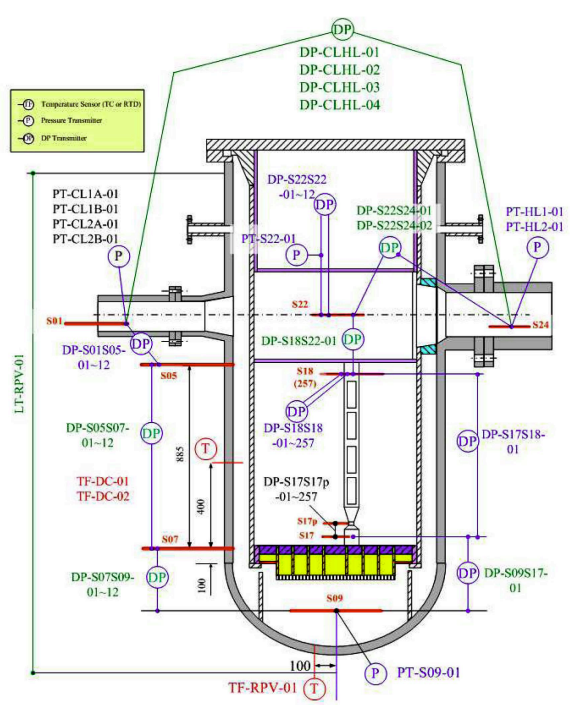

Fig. 11. Instrumentation at the Test Section

ACOP test section corresponding to the APR+ reactor vessel. In total 7 sectional pressure drops were measured for (1) the cold leg - upper downcomer (2) downcomer (3) lower downcomer - lower head (4) lower head - core inlet (5) core (6) core outlet - upper plenum and (7) upper plenum - hot leg. To get the distribution of pressure drop in azimuthal angles on a elevation plane, 12 points were selected for downcomer, core, and upper plenum regions in order to check the symmetrical nature of the flow geometry. Figure 12 shows the instrumenations in the downcomer. The core inlet flow distribution is made up of the flow rates measured at each inlet of the 257 core simulators, which were achieved at the venturi by measuring the differential pressure. The core outlet pressure distribution was obtained by measuring the differential pressure between each core outlet and the static pressure at a

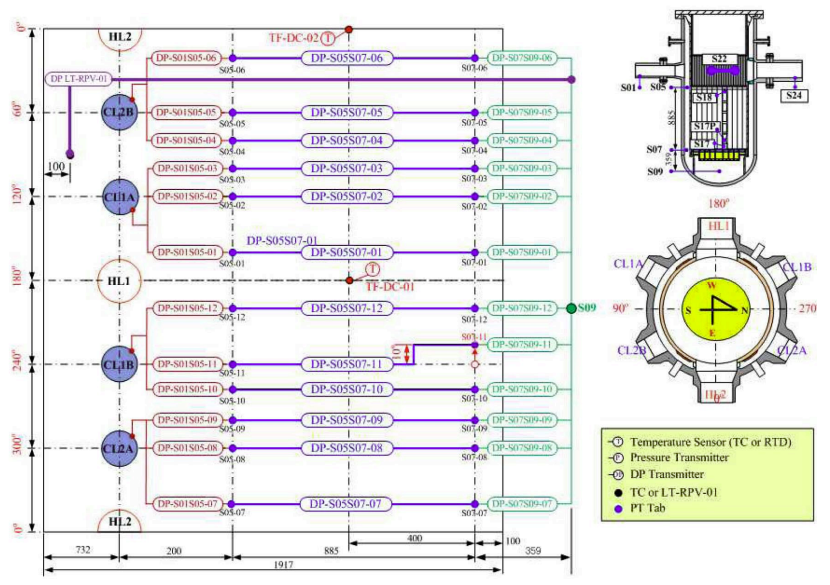

Fig. 12. Instrumentation at the Downcomer

reference core outlet point. The loop flow, pressure, and temperature were measured using vortex flow meters and smart type pressure transmitters and RTDs, respectively. In total, 9 points of static pressure, 327 differential pressures for the pressure distributions, and 257 differential pressures for the core inlet flow rates were measured with a limited number of differential pressure transmitters using sequentially operated solenoid valves. A methodology for the application of distributed instrumentation using solenoid valves was developed to measure a large amount of pressures with a limited number of pressure transmitters. (Youn et al., 2010, Euh et al., 2012b) The pressure impulse lines from the same group having similar region and working ranges were combined into a common header with solenoid valves at each line. From the common header, only one pressure delivery tube is connected to a pressure transmitter. By programming the sequential control logic for operating the solenoid valves, several numbers of pressure points 
can be measured with a single sensor automatrically. Figure 13 shows a photograph in which sequential valve networks were installed for the multi-point pressure measurements. For the control and measurement the primary system temperature, 9 RTDs were installed.

\section{REQUIREMENT FOR DATA}

The current test was performed to measure the parameters described in the test requirement report (Chang et al., 2011) which is summarized as follows:

1) Reactor inlet flow (cold leg flow)

2) Reactor outlet flow (hot leg flow)

3) Each fuel assembly inlet flow (core inlet flow distribution)

4) Each fuel assembly outlet pressure (core outlet pressure distribution)

5) Sectional pressure drops between cold leg nozzle and hot leg nozzles

6) Upper plenum pressure distribution

Table 2 shows the measurement parameters with unnormalized and normalized forms respectively. The

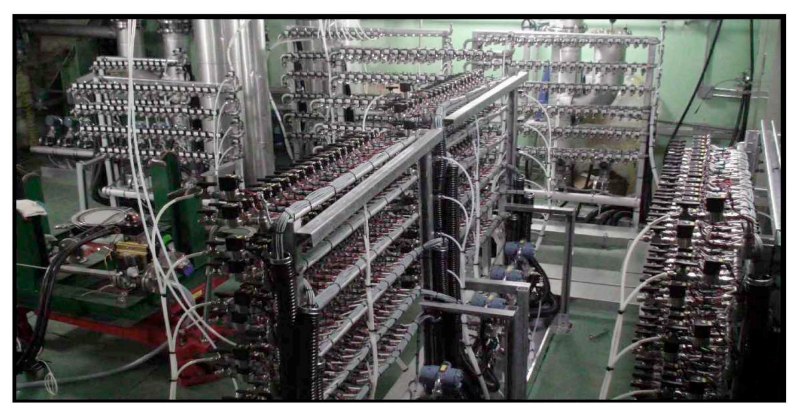

Fig. 13. Sequential Valve Network for the Multi-point Pressure Measurements required test matrix consists of (1) 15 balanced four-cold leg flow conditions, (2) 5 unbalanced four-cold leg flow conditions and (3) 9 three-pump operation conditions representing a single pump failure. Among them, the current study is dealing with only the first group tests. The allowable data scatters were shown in Table 3.

\section{TEST RESULTS}

\subsection{Major Boundary Conditions}

The major flow parameters were summarized in Table 4, which are the ensemble averaged value of 15 independent

Table 3. Maximum Allowable Data Scatter

\begin{tabular}{c|c}
\hline Parameter & Allowable Criteria \\
\hline Each core simulator inlet flow distribution & $\pm 1.5 \%^{(1)}$ \\
\hline Each core simulator outlet pressure distribution & $\pm 2 \%^{(2)}$ \\
\hline Sectional Pressure Loss Coefficient & $\pm 4 \%^{(3)}$ \\
\hline Mass balance at core inlet & $\pm 2 \%$ \\
\hline Mass balance at core outlet & $\pm 2 \%$ \\
\hline Pressure deviation at upper plenum & $\pm 2 \%^{(4)}$ \\
\hline
\end{tabular}

(1) $s_{i}=100\left[\frac{1}{N-1} \sum\left(\frac{W_{i, j}-\overline{W_{l}}}{\overline{W_{l}}}\right)^{2}\right]^{1 / 2}$

(2) $s_{i}=100\left[\frac{1}{N-1} \sum\left(E_{i, j}-\bar{E}_{l}\right)^{2}\right]^{1 / 2}$

(3) $s_{i}=100\left[\frac{1}{N-1} \sum\left(\frac{K_{i, j}-\overline{K_{l}}}{\overline{K_{l}}}\right)^{2}\right]^{1 / 2}$

(4) $s_{i}=100\left[\frac{1}{N-1} \sum\left(\frac{P_{i, j}-\bar{P}_{l}}{\bar{P}_{l}}\right)^{2}\right]^{1 / 2}$

$\mathrm{N}$ : Total number of tests

Table 2. Measuring Parameters

\begin{tabular}{c|c|c}
\hline Parameter & Un-Normalized Form & Normalized Form \\
\hline Core Simulator Inlet Flow Rate & $\mathrm{W}_{\text {core inlet }, i}$ & $\frac{W_{\text {core inlet }, i}}{\overline{W_{\text {core inlet }}}}$ \\
\hline Core Simulator Outlet Pressure & $P_{\text {exit }}$ & $E_{\text {Exit }, i}=\frac{P_{\text {exit }, i}-\overline{P_{\text {exit }}}}{\overline{P_{\text {lnlet }}}-\overline{P_{\text {exlt }}}}$ \\
\hline Sectional Pressure Drop & $\Delta P_{i}$ & $K_{i, j}=\frac{\Delta P_{i, j}}{V H_{\text {station }, 1}}$ \\
\hline Mass Balance of Reactor Inlet Flow & - & $\epsilon_{1}=\frac{\sum W_{\text {inlet nozzle }, i}-\sum W_{\text {core inlet }, j}}{\sum W_{\text {inlet nozzle }, i}}$ \\
\hline Mass Balance of Reactor Outlet Flow & - & $\epsilon_{2}=\frac{\sum W_{\text {inlet nozzle }, i}-\sum W_{\text {outlet nozzle }, j}}{\sum W_{\text {inlet nozzle }, i}}$ \\
\hline Upper Plenum Pressures & $P_{i}$ &
\end{tabular}


test results. The 8 static pressures measured at primary system have standard deviation of $0.31 \%$ to $0.57 \%$ for the 15 test cases. In the similar way, each measured temperature has $0.1 \sim 0.14 \%$ of standard deviations. The loop flows are very accurately controlled, which have shown less than $0.024 \%$ of standard deviations for the data of 15 tests.

\subsection{Mass Balance}

To check the consistency of the measured data, two kinds of balances were analyzed: balance of mass and pressure drop. The mass flow can be obtained at three locations: 4 cold legs, core inlet by 257 core simulators, and 2 hot legs. The total reactor flow rate by the summation of the four cold leg flows was set as a basis of the comparison. Since the current test does not simulate the core bypass flow, the three total reactor flows should be agreed with each other. The definition of the mass balance as follows:

$$
\begin{gathered}
\epsilon_{1}=\frac{\sum W_{\text {inlet nozzle }, i-\sum W_{\text {core inlet }, j}}}{\sum W_{\text {inlet nozzle }, i}} \\
\epsilon_{2}=\frac{\sum W_{\text {inlet nozzle }, i}-\sum W_{\text {outlet nozzle }, j}}{\sum W_{\text {inlet nozzle }, i}}
\end{gathered}
$$

Table 4. Major Test Conditions

\begin{tabular}{c|c|c}
\hline Parameter & Values & Comment \\
\hline Pressure $1, \mathrm{kPa}$ & 375.3 & PT-CL1A-01 \\
\hline Total Loop Flow, kg/s & 540.0 & Sum of the Loop Flow \\
\hline Loop-01, kg/s & 135.0 & QV-CL1A-01-M \\
\hline Loop-02, kg/s & 135.0 & QV-CL1B-01-M \\
\hline Loop-03, kg/s & 135.0 & QV-CL2A-01-M \\
\hline Loop-04, kg/s & 135.0 & QV-CL2B-01-M \\
\hline Temperature, ${ }^{\circ} \mathrm{C}$ & 59.9 & TF-CL1A-01 \\
\hline
\end{tabular}

Table 5 shows the statistical results for the mass balance for all test cases. The right column in the table shows the ensemble averages and standard deviations. The summation of the 257 core simulators shows a $2.3 \%$ underestimation of the total flow, and the reactor flow measured at hot legs has $0.4 \%$ deviation from the reference reactor flow rate. Therefore, the consistency of the flow rate can be judged as fairly good. The standard deviations of each balance were $0.018 \%, 0.015 \%$. The reference reactor flow measured at cold legs was 540 $\mathrm{kg} / \mathrm{s}$ with $0.00075 \%$ of standard deviation demonstrates good repeatability

\subsection{Balance of Pressure Drop}

The total pressure drop of the major flow path inside the APR+ reactor vessel can be obtained using the differential pressure of DP-CLHL-01 04 in figure 10. The total pressure drop should be matched to the summation of sectional pressure drops along the major flow path. The total pressure drops obtained by the above two methods show congruency with the discrepancy of $2.0 \%$ as shown in Table 6.

\subsection{Core Inlet Flow Distribution}

Figure 14 shows the results of the core inlet flowrate distribution. The dark point where the core flow is low is coincident with the location of the ICI nozzles. The results show that the core inlet flow distribution covers $86.0 \%$ to $126 \%$ of the average fuel assembly flow rate, of which the minimum value is considered to be a relatively large flow ratio when compared with other system results, which can be considered as advantageous for the thermal margin of the reactor. The data repeatability can be evaluated by the standard deviations of the averaged values for each core simulator. Figure 15 shows the standard deviations of normalized core inlet flow distributionat each core simulator, which have $0.05 \sim 0.43 \%$. The repeatability satisfy the data requirement quite well.

\subsection{Core Outlet Pressure Distribution}

The core outlet pressure distribution were identified

\begin{tabular}{|c|c|c|c|c|c|c|c|c|c|c|c|c|c|c|c|c|c|}
\hline & 1 & 2 & 3 & 4 & 5 & 6 & 7 & 8 & 9 & 10 & 11 & 12 & 13 & 14 & 15 & \multicolumn{2}{|c|}{ Ensemble } \\
\hline Par & A-20 & A-21 & A-22 & A-23 & A-24 & A-25 & A-26 & A-27 & A-28 & A-29 & A-30 & A-32 & A-33 & A-34 & A-35 & Mean & ST.D \\
\hline Unit & $\%$ & $\%$ & $\%$ & $\%$ & $\%$ & $\%$ & $\%$ & $\%$ & $\%$ & $\%$ & $\%$ & $\%$ & $\%$ & $\%$ & $\%$ & $\%$ & \\
\hline E- & 2.31 & 2.30 & 2.29 & 2.32 & 2.31 & 2.27 & 220 & 2.30 & .28 & 2.27 & 2.28 & 2.26 & 2.28 & 2.31 & .29 & 0 & 00 \\
\hline E-mass- & 0.44 & 0.40 & 0.40 & 0.45 & 0.41 & 0.40 & 0.41 & 0.41 & 0.43 & 0.41 & 0.43 & 0.41 & 0.43 & 0.43 & 0.43 & 0.42 & 0.015 \\
\hline Unit & $\mathrm{kg} / \mathrm{s}$ & $\mathrm{kg} / \mathrm{s}$ & $\mathrm{kg} / \mathrm{s}$ & $\mathrm{kg} / \mathrm{s}$ & $\mathrm{kg} / \mathrm{s}$ & $\mathrm{kg} / \mathrm{s}$ & $\mathrm{kg} / \mathrm{s}$ & $\mathrm{kg} / \mathrm{s}$ & $\mathrm{kg} / \mathrm{s}$ & $\mathrm{kg} / \mathrm{s}$ & $\mathrm{kg} / \mathrm{s}$ & $\mathrm{kg} / \mathrm{s}$ & $\mathrm{kg} / \mathrm{s}$ & $\mathrm{kg} / \mathrm{s}$ & $\mathrm{kg} / \mathrm{s}$ & $\mathrm{kg} / \mathrm{s}$ & $\%$ \\
\hline Total Cold Leg Flow & 540.0 & 540.0 & 540.0 & 540.0 & 540.0 & 540.0 & 540.0 & 540.0 & 540.0 & 540.0 & 540.0 & 540.0 & 540.0 & 540.0 & 540.0 & 540.0 & 0.00075 \\
\hline
\end{tabular}

Table 5. Mass Balance 
by static pressure, $P_{\text {exit }}$, and relative differential pressure over the average core differential pressure as follows:

$$
E_{E x i t, i}=\frac{P_{\text {exit }, i}-\overline{P_{\text {exit }}}}{\overline{P_{\text {inlet }}}-\overline{P_{\text {exit }}}}
$$

The core outlet pressure has a range of $308 \sim 313 \mathrm{kPa}$, which corresponding to $99.4 \sim 101 \%$ of average core outlet pressure. The core outlet distribution represented by equation (3) has a range of $0.045 \sim 0.078$ and standard deviations of $0.02 \sim 2.2 \%$. Except for a specific channel, the maximum standard deviation is reduced to $0.11 \%$. Figure 16 shows the distribution of $E_{E x i t, i}$.

The upper plenum pressure was measured at 13 points on a plane. The pressure distribution has $288 \sim 299 \mathrm{kPa}$ which corresponds to $97.3 \%$ to $101 \%$ of ensemble average value. The standard deviations for the data of 15 tests have $0.45 \sim 0.47 \%$ for each measured point.

\subsection{Sectional Pressure Drop}

The sectional pressure drops were measured along the major flow path correponding to figure 11 . The pressure loss coefficients for intervals identified from the measured pressure drop data will be utilized for safety

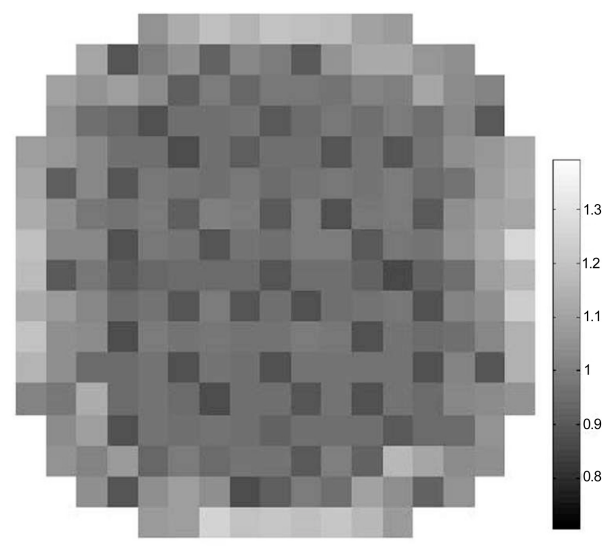

Fig. 14. Core Inlet Flow Distribution

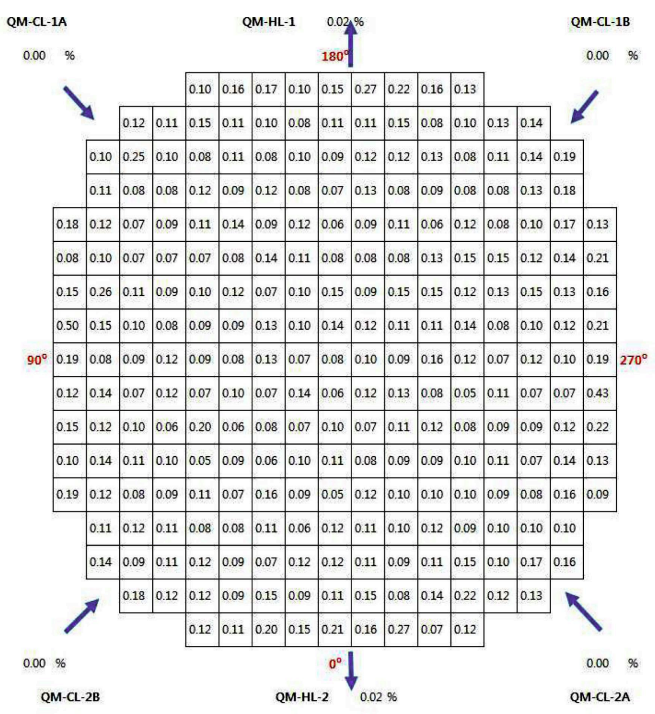

Fig. 15. Standard Deviation of Core Inlet Flow Distribution

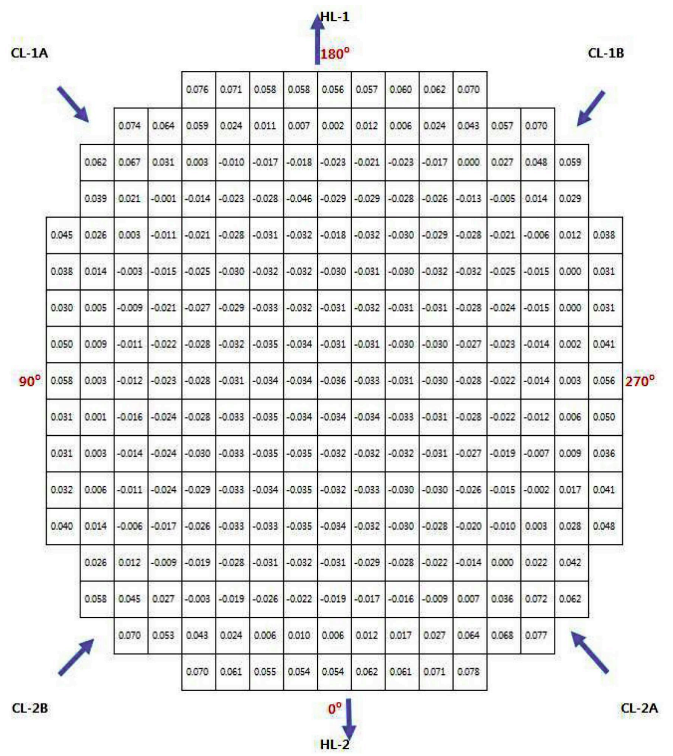

Fig. 16. Core Outlet Relative Pressure Distribution based on the Core Average Differential Pressure

Table 6. Pressure Drop Balance

\begin{tabular}{c|c|c|c|c|c|c|c|c|c|c|c|c|c|c|c|c|c}
\hline & 1 & 2 & 3 & 4 & 5 & 6 & 7 & 8 & 9 & 10 & 11 & 12 & 13 & 14 & 15 & Ensemble \\
\hline Parameter & A-20 & A-21 & A-22 & A-23 & A-24 & A-25 & A-26 & A-27 & A-28 & A-29 & A-30 & A-32 & A-33 & A-34 & A-35 & Mean & ST.D \\
\hline Unit & $\%$ & $\%$ & $\%$ & $\%$ & $\%$ & $\%$ & $\%$ & $\%$ & $\%$ & $\%$ & $\%$ & $\%$ & $\%$ & $\%$ & $\%$ & $\%$ & $\%$ \\
\hline $\begin{array}{c}(\text { DP2)-(DP1) } \\
\text { (DP1) } * 100\end{array}$ & 1.87 & 1.88 & 1.92 & 2.01 & 2.00 & 1.97 & 1.99 & 1.99 & 1.99 & 1.89 & 1.96 & 1.95 & 2.04 & 2.02 & 2.00 & 1.96 & 0.052 \\
\hline Unit & $\mathrm{kPa}$ & $\mathrm{kPa}$ & $\mathrm{kPa}$ & $\mathrm{kPa}$ & $\mathrm{kPa}$ & $\mathrm{kPa}$ & $\mathrm{kPa}$ & $\mathrm{kPa}$ & $\mathrm{kPa}$ & $\mathrm{kPa}$ & $\mathrm{kPa}$ & $\mathrm{kPa}$ & $\mathrm{kPa}$ & $\mathrm{kPa}$ & $\mathrm{kPa}$ & $\mathrm{kPa}$ & $\%$ \\
\hline DP-CLHL (DP1) & 141.8 & 141.9 & 141.8 & 141.8 & 141.9 & 141.9 & 141.8 & 141.8 & 141.8 & 141.9 & 141.9 & 141.9 & 141.9 & 141.9 & 141.8 & 141.8 & 0.028 \\
\hline
\end{tabular}

DP1: Average of differential pressure between cold legs and hot legs

DP2: Summation of sectional pressure drop 
analysis of thermal hydraulic system behaviour during a transient as well as steady-state conditions of the plant. The detailed information of data and dimensionless value to the reference dynamic head at the cold leg were summarized at the data report (Euh et al., 2012c).

\section{CONCLUSION}

For the flow and pressure distribution of the APR+ reactor, hydraulic tests were performed with a 1/5 linearly reduced scale of the ACOP test facility. To preserve the flow characteristics of prototype plant, a linear scaling method was adapted with a 1/5 length scale and 1/40 for the Reynolds number when compared with APR+ reactor. The flow distribution of APR+ reactor for the balanced four-cold leg flow conditions were identified by ensemble averaging process of 15 independent data tests. The data was produced based on the data requirement for the test parameters, required uncertainty and allowable data scatter degrees. The results showed good balance for the mass flow rate and pressure drops. The inlet flow distribution showed a high minimum channel flow when compared with previous work performed for OPR1000 or APR1400. The core exit pressure was found to have an even distribution. The flow distribution and hydraulic resistance would be utilized as (1) key input data for the safety analysis of the APR+ core thermal margin and plant transient condition, and (2) for the evaluation of soundness and hydraulic performance of the reactor design. Those can also be a benchmarking data for CFD analysis and physical model development for the complex geometry.

\section{ACKNOWLEGEMENT}

The authors would like to gratefully acknowledge the financial support of Ministry of Knowledge and Economy.

\section{NOMENCLATURE}

$\begin{array}{ll}i & : \text { serial number of core simulator } \\ W_{\text {Core inlet, } i} & : \text { inlet flow rate of } \mathrm{i} \text {-th core simulator, } \mathrm{kg} / \mathrm{s} \\ P_{\text {inlet }, i} & : \text { inlet pressure of i-th core simulator, } \mathrm{kPa} \\ P_{\text {exit }, i} & : \text { outlet pressure of i-th core simulator, } \mathrm{kPa} \\ V H_{\text {station, }, 1 i} & : \text { velocity head at station } 1 \text { (cold leg), } \mathrm{kPa} \\ W_{\text {inlet nozzle, } i} & : \text { cold leg flow, } \mathrm{kg} / \mathrm{s} \\ W_{\text {outlet nozzle, } i} & : \text { hot leg flow, } \mathrm{kg} / \mathrm{s}\end{array}$

\section{REFERENCES}

[ 1 ] Hetsroni G., Use of Hydraulic Models in Nucleaer Reactor Design, Nucl. Sci. and Eng. Vol. 28, pp. 1-11(1967)
[2 ] Lee B.J., Jang H.C., Cheong J.S., Baik S.J., and Park Y.S., A Review on the Regionalization Methodology for Core Inlet Flow Distribution Map, Journal of Korean Nuclear Society, Vol. 33, No. 4., pp. 441 456(2001)

[ 3 ] Lee K, Im I, Lee B., and Goo J., YGN $3 \& 4$ Reactor Flow Model Test, Journal of Korean Nuclear Society, Vol.23, p.340(1991)

[4] Euh D.J., Kwon T.S., Youn Y.J., Bae H., Chu I.C., and Lee S.J., Hydraulic Characteristicsof SMART Reactorfor a Nominal Condition, 9th International Conference on Heat Transfer, Fluid Mechanics and Thermodynamics, Malta, (2002a)

[ 5 ] Song C.-H, Kwon T.S., Yun B.J.Choi K.Y., Kim H.Y., Jun H.G., Thermal-Hydraulic R\&Dsfor the APR+ Developmentsin KOREA, ICONE18, Xi' an, China (2010)

[6] Kwon T.S., Performance Evaluation of Direct Vessel Injection Plus (DVI+),9th International Conference on Heat Transfer, Fluid Mechanics and Thermodynamics, Malta (2012a)

[ 7 ] Kwon T.S., Kang K.H., Euh, D.J., Performance Validation of Advanced Safety Featuresof APR+, The 18th Pacific Basin Nuclear Conference (PBNC 2012), Busan, Korea (2012b)

[ 8 ] Korea Hydro \& Nuclear Power Co. LTD., Advanced Power Reactor Plus Drawing, 9-120-z-175-001C, KHNP, KOREA (2011)

[9] Euh, D.J., Cho S., Youn Y.J., Kim J.T., Kang H.S., and Kwon T.S., Development of a Test Facility to Simulate the Reactor Flow Distribution of APR+, Transactions of the Korean Nuclear Society Spring Meeting, Taebaek, KOREA (2011)

[10] Bae, J.H., Euh, D.J., and Kwon T.S., Numerical simulation for a core simulator of ACOP, Transactions of the Korean Nuclear Society Spring Meeting, Taebaek, KOREA (2011)

[11] Kim K.H., Chu I.C., Euh D.J., and Kwon T.S., Calibration Tests of Fuel Assembly Simulators of APR+ Reactor, Transactions of the Korean Nuclear Society Spring Meeting, Kyungju, KOREA, (2012)

[12] Youn Y.J., Euh,D.J., Chu I.C., and Kwon T.S., Performance Test of Solenoid Valves for Multi-Points Pressure Measurement, Transactions of the Korean Nuclear Society Autumn Meeting, Korea, (2010)

[13] Chang H.C, Lim I.Y., Lee K.W.,andSeo S.T., Reactor Flow Distribution (Model) Test Requirements for APR+, 11A94-FS-TR211-00, Rev. 01, KEPCO-E\&C(2011)

[14] Euh D.J., Youn Y.J., Kim J.T., Bae J.H., Chu I.C., Kim K.H., Park C.K., and Kwon T.S.,, Installation Report of APR+ Flow Distribution Test Facility, APR+-COASISDD-15, Rev.00, KAERI (2012b)

[15] Euh D.J., Youn Y.J., Chu I.C., Kim J.T., Kim K.H., Lee S.T., andKwon T.S., A Data Report of APR+ Reactor Flow Distribution Test for 4 Pump Running Conditions, APR+-COASIS-TR-009, Rev. 0, KAERI, Korea(2012c) 